\title{
Study of Quality Management in Construction Projects
}

\author{
Tan Chin-Keng \\ International Islamic University Malaysia, Kuala Lumpur, Malaysia \\ Abdul-Rahman, Hamzah \\ University of Malaya, Kuala Lumpur, Malaysia
}

\begin{abstract}
This research explores preliminarily the practices of quality management, management commitment in quality management, and quality management implementation problems in construction projects in the context of Malaysian construction industry. The research applies semi-structured interview approach with twelve project management practitioners. The findings of the study indicate that the state of quality management in construction projects in Malaysia needs to be strengthened and there are problems in relation to quality management implementation that require attention and further research. The paper provides an insight on the state of quality management in construction projects in Malaysia.
\end{abstract}

Keywords: quality management, construction project management, practices, management commitment, problems

\section{Introduction}

The concept of quality management is to ensure efforts to achieve the required level of quality for the product which are well planned and organized. From the perspective of a construction company, quality management in construction projects should mean maintaining the quality of construction works at the required standard so as to obtain customers' satisfaction that would bring long term competitiveness and business survival for the companies (Tan \& Abdul-Rahman, 2005). Quality management is critically required for a construction company to sustain in current construction market which is highly challenging and competitive. Harris and McCaffer (2001) explained that quality management has to provide the environment within which related tools, techniques and procedures can be deployed effectively leading to operational success for a company. The role of quality management for a construction company is not an isolated activity, but intertwined with all the operational and managerial processes of the company.

\section{Literature Review}

\section{Practices of Quality Management}

Total quality management (TQM) is often defined as a complete management philosophy that permeates every aspect of a company and places quality as a strategic issue. It is accomplished through an integrated

Tan Chin-Keng, Ph.D., Kulliyyah of Architecture and Environmental Design, International Islamic University Malaysia.

Abdul-Rahman, Hamzah, Ph.D., Professor, Faculty of Built Environment, University of Malaya.

Correspondence concerning this article should be addressed to Tan Chin-Keng. E-mail: tan_chinkeng@yahoo.com. 
effort between all levels of a company to increase customer satisfaction by continuously improving current performance (Biggar, 1990). The adoption of TQM in construction industry has been promoted in some literatures (Low \& Teo, 2004; Biggar, 1990; Haupt \& Whiteman, 2004). ISO certification is nowadays a trend in most industries including construction industry. The ISO 9001 standard is now on its year 2000 revision. The five clauses for its implementation are quality management system, management responsibility, resource management, product realization, and measurement, analysis, and improvement. The application of ISO standards has received much attention from researchers. Moatazed-Keivani, Ghanbari-Parsa and Kagaya (1999) argued that the ISO 9000 standards series can form and have formed the basis for an efficient and advantageous quality management system in the construction industry. Dissanayaka, Kumaraswamy, Karim and Marosszeky (2001) stressed that the motivators behind the implementation of ISO 9000-certified quality systems for Hong Kong constructors appear to be to qualify for public works tenders, to meet clients'/customers' expectations and to improve the quality of work done. Love, Li, Irani and Faniran (2000) commented that ISO 9000 certification is not an option but rather a reality for construction companies that wish to retain and sustain their competitiveness in today's highly competitive markets. Liu (2003) stated that it is indicative that ISO 9000 has an impact on the contractors' attitude towards quality.

As for the implementation of quality management in project management, the concepts of quality planning (identification of quality standards), quality assurance (evaluation of overall project performance) and quality control (monitoring of specific project results) in the quality management processes were defined by Project Management Institute (2000). Several tools and techniques were identified as part of the implementation process, there are, benefit/cost analysis, benchmarking, flow-charting, design of experiments, cost of quality, quality audits, inspection, control charts, pareto diagrams, statistical sampling, flow-charting and trend analysis.

Mathews, Ueno, Kekale, Repka, Pereira and Silva (2001) divided quality tools and techniques that are in support of quality programs into three main types, i.e., hard quality tools, mixing methods and soft methods. Hard quality tools are formal quality systems, documented quality systems, quality costs, control charts, and statistical sampling standards. Mixing methods are strategy and action plans review, flexibility of organization structure, control charts, quality circles, and quality planning tools. Soft methods are training, customer satisfaction surveys, regular contact with vendors and external organizations, actions to optimize environment impact, empowerment, self-assessment, and benchmarking.

\section{Management Commitment in Quality Management Implementation}

Taylor et al. (2003) concluded that senior managers' involvement, understanding and customer focus are essential antecedents of TQM success. Samson et al. (1999) described that leadership and human resources management are among strong predictors of performance TQM practices.

On construction related research, Low et al. (2004) commented that top management commitment as one of the elements that would reflect TQM performance measures in construction firms. Chin et al. (2003) found that top management commitment is the most critical factor for the successful implementation of ISO 9000. Haupt et al. (2004) argued that high levels of management actions would lead to reduced prevalence of the problems as TQM is deployed in construction sites. Arditi et al. (1997) emphasized that management 
commitment to quality and to continuous quality improvement is very important in each phase of the building process. Biggar (1990) recommended that management must fully understand and support the TQM process and actively participate in its implementation rather than delegate it.

One of the issues arise in discussing the management commitment is the conceptualization of the term. Different authors have defined it in their own ways although some similarities are observed, and the details are shown in Table 1.

Table 1

Conceptual Definition for Management Commitment

\begin{tabular}{|l|l|}
\hline Author (Year) & Element(s) in conceptual definition for management commitment. \\
\hline Rodgers et al. (1993) & Goal setting, feedback, participation. \\
\hline Arditi et al. (1997) & Top priority. \\
\hline Samson et al. (1999) & Leadership. \\
\hline Chin et al. (2003) & $\begin{array}{l}\text { Common goal setting, management review and continuous improvement, management involvement and } \\
\text { leadership, management attitude to change. }\end{array}$ \\
\hline Low et al. (2004) & Allocation of budget, planning for change, providing methods for monitoring progress of construction works. \\
\hline Haupt et al. (2004) & Initiative for successful implementation, support. \\
\hline
\end{tabular}

In addition to the above, ISO 9001: 2000 requires the following in relation to management commitment:

- Communicating about the importance of meeting customer as well as statutory and regulatory requirements;

- Establishing the quality policy;

- Ensuring that quality objectives are established;

- Conducting management reviews;

- Ensuring the availability of resources.

\section{Problems in Quality Management Implementation}

Certain problems have been observed in relation to quality management implementation. Haupt et al. (2004) noticed several hindrances for implementing TQM in construction sites, i.e., too much paperwork, transient nature of workforce, field employees regard TQM as irrelevant, difficulty in measuring results, low bid subcontracting, and subcontractors and suppliers not interested in TQM. Tang and Kam (1999) found that the most difficult task in implementing ISO 9001 in engineering consultancies in Hong Kong is to make engineers understand and accept the system, followed by the lack of strong support from the management, and lack of effective communication. Based on interview conducted in Sweden, Landin (2000) argued that in construction process, many of the concepts in ISO 9001 are experienced as being too abstract and too difficult to comprehend. He also argued that it appears difficult for a company to improve its competitiveness and be more efficient by the use of ISO 9001 alone in view of the many stages of the construction process encompassed and the diverging interests represented. Moatazed-Keivani et al. (1999) noticed concerns in the areas of bureaucracy, cost, time consumption and interpretation in relation to the implementation of ISO 9000 standards in United Kingdom (UK) construction industry. Kumaraswamy and Dissanayaka (2000) stated that 
the three most significant negative outcomes encountered by Hong Kong contractors on ISO 9000 certification are, more paperwork, more time spent in management, and increase of bureaucracy. Abdul-Rahman (1996) observed several shortcomings related to the quality management implementation in UK, i.e., QA and QM are not implemented on a full scale, the degree of commitment is different between top management and site employees, and quality management was limited to the construction stage only. Low (1994) found that most contractors in Singapore consider human-related problems are most critical in implementing quality assurance (QA). Serpell (1999) observed cultural and operational barriers in quality system implementation. In a study of quality management of a large-scale infrastructure construction project in Hong Kong, Au and Yu (1999) found problems in the areas of documentation, control of quality inspection and process procedures. Lai, Weerakoon and Cheng (2002) noticed that there are weaknesses in the implementation of quality management for construction industry in Hong Kong in respect of the communication of improvement information, and teamwork structures for quality improvement. Kubal (1996) argued that the construction industry is lacking open communications and mutual support that derived from trust-based relationships among project participants to effect substantive quality improvement.

\section{Research Questions}

Based on the above review of literatures pertaining to the quality management and its implementation in construction projects focusing on the issues of practices, management commitment and problems, the authors observe that articles or research outputs (in international academic journals) on the subject matters in the context of construction industry in Malaysia are seriously lacking. Hence, gaps of understanding on the following (in the context of construction industry in Malaysia, and more specifically, the construction projects) questions are obvious and require attention:

(1) How the quality management is been practiced?

This research question is further elaborated to more specific questions as below:

- Has formal quality management system (e.g., ISO 9000) been widely practiced?

- Is the philosophy of TQM adopted?

- What are the quality management tools and techniques commonly applied?

(2) To what extent the management of construction companies is perceived as committed towards quality management implementation?

This research question would specifically towards find the commitment of management from the following perspectives:

- Leadership and participation.

- Allocation of resources.

(3) What are the problems encountered in relation to the implementation of quality management?

This research question would verify if quality management implementation related problems encountered elsewhere also faced by local practitioners. Also, it would find out any others which have not been reported (if any).

The answers to the above questions are hoped to fill the gap of understanding pertaining to quality 
management in construction projects in the context of construction industry in Malaysia.

\section{Objectives}

This research is the preliminary study of a doctorate research on overcoming the problems in implementation of quality management in construction projects in Malaysia. It is an exploratory study in nature aimed to ascertain perceptions and experiences of practitioners in the industry in the below:

(1) Practices of quality management in construction projects from the perspective of tools and techniques applied;

(2) Level of commitment of management towards the implementation of quality management in construction projects;

(3) Problems in relation to the implementation of quality management in construction projects.

\section{Methodology}

This study adopted in-depth semi-structured interviews which were conducted with representatives from construction companies. Similar approach has been applied in some other researches on the implementation and effectiveness of quality management systems in the UK construction industry (Moatazed-Keivani et al., 1999; Abdul-Rahman, 1996; Shammas-Toma et al., 1996). Such approach is deemed to be suited to the aims of this study which is concerned primarily with ascertaining the perceptions and experiences of practitioners in the industry (Moatazed-Keivani et al., 1999).

Selection of sample was based on convenience sampling approach where the authors obtained the sampling units that were convenience available (Frankfort-Nachmias et al., 2000) from the personal contacts of the authors or contacts through recommendation from friends of authors. Cooper and Schindler (1998) proposed that in the early stage of an exploratory research, where the researcher is seeking guidance, to test ideas, or even to gain ideas about a subject of interest, such approach might be applicable. Nevertheless, to increase the validity of the study, certain criteria had been set. Firstly, the sample must be construction companies registered with the Construction Industry Development Board (CIDB) Malaysia, and secondly, the interviewees must be currently involve in project management. Although problems had been encountered in getting consent from construction companies to be interviewed, the authors managed to obtain 12 respondents. Each interview session was taking one to one-and-a-half hour.

\section{Profile of Samples}

All sample organizations are G7 (highest grade) construction companies under CIDB registration. They are generally construction companies for building works, some (e.g., No. 4 \& No. 5) involve also in infrastructure works actively at the moment. Before each interview session was conducted, the authors had communicated to the organization about the nature and purpose of the study, this was to make possible for the organizations to assign the most appropriate person to be interviewed. The detail profiles of respondents are as illustrated in Table 2 . 
Table 2

Profiles of Respondents

\begin{tabular}{llr}
\hline Respondent & Position & Years of experience \\
\hline 1 & Project manager & 10 \\
2 & Project manager & 18 \\
3 & Project director & 20 \\
4 & Executive director & 12 \\
5 & Project manager & 11 \\
6 & Quality system manager & 11 \\
7 & Management systems manager & 12 \\
8 & Project coordinator & 8 \\
9 & Assistant general manager & 15 \\
10 & Project engineer & 4 \\
11 & Project manager & 15 \\
12 & Project manager & 9 \\
\hline
\end{tabular}

Analysis and Findings

\section{Practices of Quality Management}

Quality management system. There are five ISO 9001 certified companies out of twelve companies interviewed. Two out of seven non-ISO certified companies are currently working towards getting certified. "ISO is a current trend in the industry, in order not to loss out in the competition, we have no choice, but to have it”, one respondent said. Most of the respondents from the ISO companies said that the system provides systematic guidelines for the implementation of quality management, however, it was interesting to note that they agreed that marketing purpose is the main consideration for obtaining ISO certification. As for the TQM, none of the companies is currently practicing it. The companies without formal quality management system (ISO certification) claimed that they practice quality management by their own approaches.

It is perceived that quality management is part of project management and concern of every company interviewed. However, the purpose of quality management is mainly for fulfilling their obligation under the construction contract rather than increasing customer satisfaction as emphasized in the philosophy of TQM. "As far as company is concerned, profit still the focus. If our works not achieve the satisfaction of the SO (Superintending Officer), we have to redo, and it bring losses to us", a respondent commented.

Quality management tools and techniques. A list of quality management tools and techniques was prepared based on the review of literatures. Item of the list is shown in Table 3. It is one of the objectives of the study to verify to what extent the tools and techniques stated are relevant in the local context of construction project management. The design of experiment and inspection are seem as the common practices to all. Design of experiment is used for conducting various types of test, e.g., concrete test, etc.. Meanwhile, site supervisors are engaged in every project to supervise and inspect the construction works. Except for the two mentioned, there is no any other quality management tools or techniques that is common to all. Quality audits (internal audit and external audit) are common to those ISO 9001 certified companies only. Some non-ISO companies might have 
gone through quality audits, but that were mainly the external audits by their clients or consultants. Few quality management tools and techniques were revealed from the interviews which were not highlighted in the literatures are project quality plans, weekly site reports, and work method statements. A project quality plan is prepared normally upon request of the client or consultants. Weekly site reports are used as the monitoring tools of site activities whereas work method statements are used as guidelines for operation on sites. Details of quality management tools and techniques applied by companies interviewed are illustrated in Table 3.

Table 3

Quality Management Tools and Techniques Applied by Construction Companies

\begin{tabular}{|c|c|c|c|c|c|c|c|c|c|c|c|c|c|c|}
\hline & & & & & & Resp & dent & & & & & & Totol & Percent \\
\hline & 1 & 2 & 3 & 4 & 5 & 6 & 7 & 8 & 9 & 10 & 11 & 12 & lotal & $(\%)$ \\
\hline Benefit/cost analysis & & & & & & $\checkmark$ & & & & & $\checkmark$ & $\checkmark$ & 3 & 25 \\
\hline Benchmarking & & & & & & $\checkmark$ & & $\checkmark$ & & & $\checkmark$ & & 3 & 25 \\
\hline Flow-charting & & $\checkmark$ & & & & $\checkmark$ & & $\checkmark$ & & $\checkmark$ & $\checkmark$ & & 5 & 42 \\
\hline Designs of experiment & $\checkmark$ & $\checkmark$ & $\checkmark$ & $\checkmark$ & $\checkmark$ & $\checkmark$ & $\checkmark$ & $\checkmark$ & $\checkmark$ & $\checkmark$ & $\checkmark$ & $\checkmark$ & 12 & 100 \\
\hline Cost of quality & & & & & & $\checkmark$ & & & & & $\checkmark$ & & 2 & 17 \\
\hline Quality audits & & & $\checkmark$ & $\checkmark$ & $\checkmark$ & $\checkmark$ & $\checkmark$ & & $\checkmark$ & & $\checkmark$ & & 7 & 58 \\
\hline Inspection & $\checkmark$ & $\checkmark$ & $\checkmark$ & $\checkmark$ & $\checkmark$ & $\checkmark$ & $\checkmark$ & $\checkmark$ & $\checkmark$ & $\checkmark$ & $\checkmark$ & $\checkmark$ & 12 & 100 \\
\hline Control charts & & & & & & $\checkmark$ & & $\checkmark$ & & $\checkmark$ & $\checkmark$ & & 4 & 33 \\
\hline Pareto diagram & & & & & & $\checkmark$ & & & & & & & 1 & 8 \\
\hline Statistical sampling & & & & & & $\checkmark$ & & $\checkmark$ & & $\checkmark$ & $\checkmark$ & $\checkmark$ & 5 & 42 \\
\hline Trend analysis & & & & & & $\checkmark$ & & & & $\checkmark$ & & & 2 & 17 \\
\hline Any others mentioned & & $\checkmark$ & $\checkmark$ & $\checkmark$ & $\checkmark$ & $\checkmark$ & $\checkmark$ & & $\checkmark$ & & & & 7 & 58 \\
\hline
\end{tabular}

\section{Management Commitment in Quality Management Implementation}

Leadership and participation. Three questions were asked to each respondent to elicit the level of leadership and participation exhibited by the top management of the respective company. The answer of "yes" reflects leadership and participation of the top management is exhibited, whilst the answer of "no" indicates the lack of leadership and participation. The questions were:

(1) Does your top management ever communicate to the subordinate of the importance of meeting customer requirements?

There were nine out of twelve (75\%) respondents answered "yes" to the above question. Apparently, top management of most of the companies do communicate about the importance of meeting customer requirements, however, it is noted that their concerns are mainly to avoid problems instead of achieving excellence in their works. "My boss is concerned about thecost and time implications if the construction works do not meet the expectation of client/consultants".

(2) Does your top management lead in setting quality policies?

There were six out of twelve (50\%) respondents answered "yes" to the above question. The answers for the other half of the respondents were either there were not quality policies in their organizations, or the top management delegated the task to others.

(3) Does your top management conduct management reviews on project quality? 
There were eight out of twelve (67\%) respondents answered "yes" to the above question. It is not surprisingly for the ISO 9001 certified companies provide a favorable answer to the question as it is part of the requirements. For those non-ISO companies, the reviews are not purposely conducted on project quality, but for project as a whole. Some respondents commented that cost and time are generally received more attention in such reviews.

Details for the feedbacks from the respondents on the above three questions are illustrated in Table 4.

Table 4

State of Leadership and Participation of Top Management in Quality Management

\begin{tabular}{|l|c|c|c|c|c|c|c|c|c|c|c|c|c|c|c|}
\hline & \multicolumn{9}{|c|}{ Respondent } & \multicolumn{3}{c|}{ Total } & $\begin{array}{c}\text { Percent } \\
\text { (\%) }\end{array}$ \\
\hline & 1 & 2 & 3 & 4 & 5 & 6 & 7 & 8 & 9 & 10 & 11 & 12 & \\
\hline Communicate the importance of meeting customer requirements & $\checkmark$ & & $\checkmark$ & $\checkmark$ & $\checkmark$ & $\checkmark$ & $\checkmark$ & $\checkmark$ & $\checkmark$ & & $\checkmark$ & & 9 & 75 \\
\hline Setting quality policies & $\checkmark$ & & $\checkmark$ & & $\checkmark$ & $\checkmark$ & $\checkmark$ & & $\checkmark$ & & & & 6 & 50 \\
\hline Conduct management reviews on project quality & & & $\checkmark$ & & $\checkmark$ & $\checkmark$ & $\checkmark$ & & $\checkmark$ & $\checkmark$ & $\checkmark$ & $\checkmark$ & 8 & 67 \\
\hline
\end{tabular}

Allocation of resources. Two questions were asked on the aspect of allocation of resources, the questions were as below:

(1) As for quality management in your project is concerned, do you recommend the allocation for financial resources to be increased?

(2) As for quality management in your project is concerned, do you recommend the allocation for human resources to be increased?

The purpose of the above two questions is to ascertain if the allocation of financial and human resources respectively for the implementation of quality management in construction projects are sufficient. It is considered that the answer of "yes" signifies that the allocation is not sufficient, whereas the answer of "no" signifies that the allocation is sufficient.

They were seven out of twelve (58\%) respondents answered "yes” to both questions respectively. Interestingly, answers for the first and second questions were identical for all respondents. Meaning that, those answered "yes" to the question (1) also answered the same to the question (2). Those answered "no" to the question (1) also answered the same to the question (2). Details for the feedbacks from the respondents are illustrated in Table 5.

Table 5

State of Resources Allocation of Top Management for Quality Management

\begin{tabular}{|c|c|c|c|c|c|c|c|c|c|c|c|c|c|c|}
\hline & \multicolumn{12}{|c|}{ Respondent } & \multirow{2}{*}{ Total } & \multirow{2}{*}{$\begin{array}{c}\text { Percent } \\
\text { (\%) }\end{array}$} \\
\hline & 1 & 2 & 3 & 4 & 5 & 6 & 7 & 8 & 9 & 10 & 11 & 12 & & \\
\hline Seek to have more financial resources & $\checkmark$ & $\checkmark$ & $\checkmark$ & $\checkmark$ & & & & & $\checkmark$ & $\checkmark$ & & $\checkmark$ & 7 & 58 \\
\hline Seek to have more human resources & $\checkmark$ & $\checkmark$ & $\checkmark$ & $\checkmark$ & & & & & $\checkmark$ & $\checkmark$ & & $\checkmark$ & 7 & 58 \\
\hline
\end{tabular}

\section{Problems in Quality Management Implementation}

The respondents were asked if they encounter problems as highlighted in the literatures as for the implementation of quality management is concerned. List of problems was as shown in Table 6. In addition to that, they were also asked to state other problems in the implementation of quality management faced if there is 
any. Apparently, all problems that were highlighted in literatures are relevant. Problems with subcontractors' works (83\%), problem with more paper works (75\%), and increase of time (75\%) were the three main problems highlighted. Other problems which are encountered by at least half of the respondents are unwillingness of project staff to accept the quality system (67\%), inadequate technical expertise/skills (67\%), increase of cost (58\%), and ineffective communication (50\%). As for the problem which was not discussed in the literatures, one respondent pointed out those external factors such as contract amount, efficiency of consultants also have implication on the implementation of quality management. Details for the feedbacks from the respondents are illustrated in Table 6.

Table 6

Quality Management Implementation Problems Encountered by Construction Companies

\begin{tabular}{|l|c|c|c|c|c|c|c|c|c|c|c|c|c|c|}
\hline & \multicolumn{9}{|c|}{ Respondent } & \multicolumn{2}{c|}{ Total } & $\begin{array}{c}\text { Percent } \\
\text { (\%) }\end{array}$ \\
\hline & 1 & 2 & 3 & 4 & 5 & 6 & 7 & 8 & 9 & 10 & 11 & 12 & \\
\hline Inadequate management support & $\checkmark$ & & & & & & & & & $\checkmark$ & & $\checkmark$ & 3 & 25 \\
\hline Unwillingness of project staff to accept the quality system & $\checkmark$ & $\checkmark$ & & $\checkmark$ & & & $\checkmark$ & $\checkmark$ & $\checkmark$ & $\checkmark$ & & $\checkmark$ & 8 & 67 \\
\hline Difficulties in understanding the quality system & & $\checkmark$ & & $\checkmark$ & & & & $\checkmark$ & & & & $\checkmark$ & 4 & 33 \\
\hline Problem with more paper works & & $\checkmark$ & $\checkmark$ & $\checkmark$ & $\checkmark$ & & $\checkmark$ & $\checkmark$ & $\checkmark$ & $\checkmark$ & & $\checkmark$ & 9 & 75 \\
\hline Problem with documentation & & $\checkmark$ & & $\checkmark$ & $\checkmark$ & & & $\checkmark$ & & $\checkmark$ & & & 5 & 42 \\
\hline Difficulties in measuring results & & & & $\checkmark$ & & & & $\checkmark$ & & $\checkmark$ & $\checkmark$ & $\checkmark$ & 5 & 42 \\
\hline Problems with subcontractors' works & $\checkmark$ & $\checkmark$ & & $\checkmark$ & $\checkmark$ & & $\checkmark$ & $\checkmark$ & $\checkmark$ & $\checkmark$ & $\checkmark$ & $\checkmark$ & 10 & 83 \\
\hline Ineffective communication & $\checkmark$ & $\checkmark$ & & $\checkmark$ & & & & & $\checkmark$ & $\checkmark$ & $\checkmark$ & & 6 & 50 \\
\hline Increase of cost & $\checkmark$ & $\checkmark$ & & $\checkmark$ & & & & $\checkmark$ & & $\checkmark$ & $\checkmark$ & $\checkmark$ & 7 & 58 \\
\hline Increase of time & & $\checkmark$ & $\checkmark$ & $\checkmark$ & $\checkmark$ & & $\checkmark$ & $\checkmark$ & & $\checkmark$ & $\checkmark$ & $\checkmark$ & 9 & 75 \\
\hline Inadequate information & & $\checkmark$ & & & & & & $\checkmark$ & & $\checkmark$ & & $\checkmark$ & 4 & 33 \\
\hline Inadequate technical expertise/skills & $\checkmark$ & $\checkmark$ & & $\checkmark$ & & & & $\checkmark$ & $\checkmark$ & $\checkmark$ & $\checkmark$ & $\checkmark$ & 8 & 67 \\
\hline Any others mentioned & & & & & $\checkmark$ & & & & & & & & 1 & 8 \\
\hline
\end{tabular}

\section{Conclusions}

Based on the findings of the preliminary study on the implementation of quality management in construction projects in the context of construction industry in Malaysia, several points can be preliminarily concluded:

(1) Total quality management is not a common practice;

(2) ISO registration is mainly for marketing purpose;

(3) Implementation of quality management is greatly perceived as a mean to fulfill contractual obligations instead of satisfying the needs of clients;

(4) In terms of quality management tools and techniques, construction companies are commonly using the traditional methods such as experiments and inspections. Other methods might be used depend on the individual practices of a company or requirements from client/consultants;

(5) Leadership and participation of top management of construction companies in quality management need to be strengthened;

(6) Allocation of financial and human resources for the purpose of problems of the implementation of 
quality management should be further increased;

(7) Most of the quality management implementation problems encountered elsewhere are relevant in the local context and require attention.

\section{Limitations}

Research findings are dependent upon a valid choice of research methodology, the reliability of the data gathered, and the applicability of the statistical tools used (Walker, 1997). The authors are aware of the limitations of this study and would like to highlight them as below:

(1) The sample is too small for quantitative analysis using statistical tools;

(2) The sample was obtained through convenience sampling approach which has no controls to precision (Cooper et al., 1998);

(3) The authors had no control to ensure the most appropriate person was assigned by each company to be interviewed although they had done their best;

(4) The willingness of the respondents to reveal weaknesses in their respective organization was uncertain;

(5) Due to work commitment, some respondents could not fully concentrate on during the interview sessions, this caused the intended in-depth interview could not be fully achieved.

\section{Suggestions for Further Research}

Knowing the limitation of the study, it is therefore suggested the research area of this study to be further investigated as the other part of the doctorate research, adopting the following approaches:

(1) Questionnaire survey of a large sample which enable quantitative analysis using statistical tools. Probability sampling approach should be applied in the sampling process;

(2) In-depth case studies which involving various modes of data collection (e.g., observation) to be conducted to verify data collected through perceptions of respondents in questionnaire survey;

(3) Correlations between the three elements on the study, i.e., practices of quality management, management commitment, and implementation problems to be ascertained.

\section{References}

Abdul-Rahman, H. (1996). Some observations on the management of quality among construction professionals in the UK. Construction Management and Economics, 14, 485-495.

Arditi, D., \& Gunaydin, H. M. (1997). Total quality management in the construction process. International Journal of Project Management, 15(4), 235-243.

Au, J. C. W., \& Yu, W. W. M. (1999). Quality management for an infrastructure construction project in Hong Kong. Logistics Information Management, 12(4), 309-314.

Biggar, J. L. (1990). Total quality management in construction. Transactions of the American Association of Cost Engineers, Q.1.1-Q.1.4.

Chin, K. S., \& Choi, T. W. (2003). Construction in Hong Kong: Success factors for ISO 9000 implementation. Journal of Construction Engineering and Management, November/December, 599-609.

Cooper, D. R., \& Schindler, P. S. (1998). Business research methods (6th ed.). Singapore: McGraw-Hill Book Co., 212-252.

Dissanayaka, S. M., Kumaraswamy, M. M., Karim, K., \& Marosszeky, M. (2001). Evaluating outcomes from ISO 9000-certified quality systems of Hong Kong constructors. Total Quality Management, 12(1), 29-40.

Frankfort-Nachmias, C., \& Nachmias, D. (2000). Research methods in the social sciences. New York: Worth Publishers, 161-185. 
Harris, F., \& McCaffer, R. (2001). Modern construction management (5th ed.). Oxford: Blackwell Science Ltd.

Haupt, T. C., \& Whiteman, D. E. (2004). Inhibiting factors of implementing total quality management on construction sites. The TQM Magazine, 16(3), 166-173.

ISO. (2000). ISO 9001—quality management systems—requirements. International Standard Organization, Geneva.

Kubal, M. T. (1996). The future of engineered quality. Journal of Management in Engineering, September/October, 45-52.

Kumaraswamy, M. M., \& Dissanayaka, S. M. (2000). ISO 9000 and beyond: From a Hong Kong construction perspective. Construction Management and Economics, 18, 783-796.

Lai, K. H., Weerakoon, T. S., \& Cheng, T. C. E. (2002). The state of quality management implementation: A cross-sectional study of quality-oriented companies in Hong Kong. Total Quality Management, 13(1), 29-38.

Landin, A. (2000). ISO 9001 within the Swedish construction sector. Construction Management and Economics, 18, 509-518.

Liu, A. M. M. (2003). The quest for quality in public housing projects: A behaviour-to-outcome paradigm. Construction Management and Economics, 21, 147-158.

Love, P. E. D., Li, H., Irani, Z., \& Faniran, O. (2000). Total quality management and the learning organization: A dialogue for change in construction. Construction Management and Economics, 18, 321-331.

Low, S. P. (1994, April). ISO 9000: Implementation problems in the construction industry. Quality World, 228-234.

Low, S. P., \& Teo, J. A. (2004, January). Implementing total quality management in construction firms. Journal of Management in Engineering, 8-15.

Mathews, B. P., Ueno, A., Kekale, T., Repka, M., Pereira, Z. L., \& Silva, G. (2001). European quality management practices—The impact of natural culture. International Journal of Quality \& Reliability Management, 18(7), 692-707.

Moatazed-Keivani, R., Ghanbari-Parsa, A. R., \& Kagaya, S. (1999). ISO 9000 standards: Perceptions and experiences in the UK construction industry. Construction Management and Economics, 17, 107-119.

Project Management Institute. (2000). A guide to the project management body of knowledge (PMBOK). Project Management Institute, Pennsylvania, 95-105.

Rodgers, R., Hunter J. E., \& Rogers, D. L. (1993). Influence of top management on management program success. Journal of Applied Psychology, 78(1), 151-155.

Samson, D., \& Terziovski, M. (1999). The relationship between total quality management practices and operational performance. Journal of Operational Management, 17, 393-409.

Serpell, A. (1999). Integrating quality systems in construction projects: The Chilean case. International Journal of Project Management, 17(5), 317-322.

Shammas-Toma, M., Seymour, D. E., \& Clark, L. (1996). The effectiveness of formal quality management systems in achieving the required cover in reinforced concrete. Construction Management and Economics, 14, 353-364.

Tan, C. K., \& Abdul-Rahman, H. (2005). Preliminary research into overcoming implementation problems in construction projects. Proceeding of the 4th Micra Conference. Faculty of the Built Environment, University Malaya, 15 August-28 August.

Tang, S. L., \& Kam, C. W. (1999). A survey of ISO 9001 implementation in engineering consultancies in Hong Kong. International Journal of Quality \& Reliability Management, 16(6), 562.

Taylor, W. A., \& Wright, G. H. (2003). The impact of senior managers' commitment on the success of TQM programmes—An empirical study. International Journal of Manpower, 24(5), 535-550.

Walker, D. H. T. (1997). Choosing an appropriate research methodology. Construction Management and Economics, 15, 149-159. 